\title{
An Empirical Study on the Patent Quality of Chinese Herbal Medicine Geographical Indications Industry
}

\author{
Zhi Sun \\ Intellectual Property research Institute \\ Xiamen University \\ Xiamen, China 361005 \\ Intellectual Property Center \\ Guizhou Normal University \\ Guiyang, China 550001,
}

\author{
Guifeng Feng \\ Research Institute \\ Guizhou Education University \\ Guiyang, China 550018
}

\author{
Yongzhong Qiao* \\ Intellectual Property research Institute \\ Xiamen University \\ Xiamen, China 361005 \\ *Corresponding author
}

\begin{abstract}
This paper took the authorized patent of geographical indications industry of Chinese herbal medicine as the research object, through the analysis of the types of the industry patent, technical category, legal status, maintenance information, found that the geographical indications of Chinese herbal medicine industry patents have mainly focused on design patents, technical patents, especially the invention of the proportion of patents less. Overall, the current number of geographical indications of Chinese herbal medicine industry is very limited, and the quality of patents at a low level in China.
\end{abstract}

Keywords-Chinese herbal medicine geographical indications industry; patent quality; Legal status; Maintenance time.

\section{INTRODUCTION}

As the latest and most viable technological innovation of the crystallization, the patent is a measure of independent innovation ability to quantify an important dimension [1]. According to the results of the third national census of Chinese medicine resources, there are currently 12694 kinds of Chinese medicine resources in China. Chinese herbal medicine industry has great potential for development. Chinese herbal medicine varieties publishing geographical indications product category is an important component in the General Administration of Quality Supervision, Inspection and Quarantine of the People's Republic of China (AQSIQ). According to the collected data, as of March 12, 2017, there were 202 geographical indications of Chinese herbal medicines throughout the country registered in the AQSIQ. Chinese herbal medicine geographical indications registered number of protection has not yet reached the total amount of Chinese herbal medicine resources $2 \%$. At the same time, only 111 of the registration of 202 Chinese herbal medicine geographical indications approve the use of enterprises, nearly $1 / 2$ of which has not yet approved the use of enterprises. Approved use of 111 Chinese herbal medicines geographical indications have 516 use of enterprises (including cooperatives, research institutes), and as of April 10, 2017, only 146 approved the use of enterprises have patents (including patent applications), a total of 2237 patents. This article mainly analyzes the quality of these 2237 patents.

\section{RESEARCH STATUS AND LITERATURE REVIEW}

\section{A. Research on Patent with Geographical Indication Industry}

Research on the conservation and use of geographical indications are extensive, but the combination of geographical indications and patent issues are rarely involved in China. So far only LI zu-ming (2008) [2], YANG de-qiao (2012) [3] and other scholars have thought in China, but they lack the quantitative analysis and empirical study of the problem.

\section{B. Research on Patent Quality}

Since the 21st century, the explosive growth in the number of patents worldwide has aroused the continued attention and discussion of patent quality issues around the world. Graf.S.W. (2007) [4] argues that patent quality is closely related to the patentability of technology. Trappey, Amy J.C. et al. (2012) [5] pointed out that patent transactions help determine the quality of patents. ZHU xue-zhong (2013) [6] said that the definition of patent quality can be from the application documents quality, quality of inspection, technical quality and economic quality point of view. LONG xiao-ning et al. (2015) [1] based on empirical analysis 
pointed out that the patent incentive policy has a significant impact on the number and quality of patents. QIAO yongzhong (2017) [7] proposed the analysis of the patent quality of the patent annual fee and patent maintenance time of the correlation.

\section{Research on Patent of Chinese Herbal Medicine}

Representative include: GENG sheng-yan et al (2016) [8] studied the status of traditional Chinese medicine patent application for different innovation subjects; SUN zhi-yi et al. (2016) [9] analyzed the status of technology development of Chinese wolfberry from the perspective of invention patent; ZHANG dong (2009) [10] analyzed the patentability of traditional Chinese medicine under the current patent system in China. Unfortunately, the relevant research did not carry out patent analysis from the perspective of the development of geographical indications of Chinese herbal medicine. This article as a positive attempt is to make up for these deficiencies.

\section{DATA COLLECTION AND DATABASE ESTABLISHMENT}

- Step 1: Enter the website of the AQSIQ (China protected Geographical Indication Products), Statistics of approved geographical indications for Chinese herbal medicines (The deadline is March 10, 2017), the establishment of "Chinese herbal medicine geographical indications resource database".

- Step 2: Statistics The enterprises that have approved the use of geographical indications for Chinese herbal medicines (as of March 12, 2017) and established the "Enterprise Database for the Approval of the Use of Geographical Indications of Chinese Medicinal Materials".

- Step 3: Enter the website of the State Intellectual Property Office of China to collect the patent information of the approved enterprise (patent data collection starting and ending time: March 15, 2017 to April 20, 2017). Through the data cleaning, remove the duplicate part of the patent, the formation of "Chinese herbal medicine geographical indications approved the use of corporate patent information database". A total of 2237 patents (including patent applications), of which 1663 patents have been authorized, the authorized rate of $74 \%$

Based on the "Chinese herbal medicine geographical indications approved the use of corporate patent information database", this paper uses SPSS21 software to set four variables such as patent type, technical category, legal status and patent maintenance time, so as to analyze the authorized patent, investigate the patent quality of the geographical indications industry of Chinese herbal medicine in China.

\section{DATA ANALYSIS}

\section{A. Authorized Patent Distribution of Chinese Herbal Medicine Geographical Indications Industry}

China's current "Patent Law" provides that the patent, including patents for inventions, utility model patents and design patents three types. Because the invention patent has higher requirements in the authorization conditions on the creativity and novelty, it often represents a core technology in a field, which is the most direct reflection of technological innovation. Reality for a certain type of industry or a business, by observing the proportion of invention patents, can be found throughout the industry or enterprise technical content level. The greater the proportion of invention patents, the higher the quality of its patents [11]. Based on the given database, there are 455 invention patents, accounting for $26.8 \%$ of the 1663 patents authorized by the geographical indications industry of Chinese medicinal materials; there are 318 utility model patents, accounting for $19.1 \%$; there are design patents 900 , accounting for $54.1 \%$. It can be seen that the current distribution of geographical indications of Chinese herbal medicine industry is more concentrated in the field of design patents, but invention patents and utility model patents are relatively small. In particular, the invention of the core technology of the invention patent in the authorized patent accounted for less than $1 / 3$, only the number of design patents $1 / 2$, the proportion of smaller.

\section{B. Analysis on the Technical Types of Chinese Herbal Medicine Geographical Indications Industry has Authorized Patents}

In this paper, the technical types involved in the geographical indications of Chinese herbal medicine in China are summarized as eight specific technical categories, including (1) Chinese herbal medicine cultivation, breeding technology; (2) Chinese herbal medicine processing technology; (3) traditional Chinese medicine products and processing technology; (4) Chinese herbal medicine related equipment; (5) traditional Chinese medicine derivative products and process methods; (6) traditional Chinese medicine packaging; (7) Chinese medicine quality testing equipment and Method; (8) other categories[10]. In the above specific technical categories (1) (2) (3) (4) (7) is the representative of the geographical indications of Chinese herbal medicine industry, especially the first three technologies, the number of patents can directly reflect the Chinese medicine The Technological Innovation Ability and Core Competence of Geographical Indication Industry. The technical categories of the three types of patents for the geographical indications of Chinese herbal medicines are shown in "Table I". 
TABLE I.

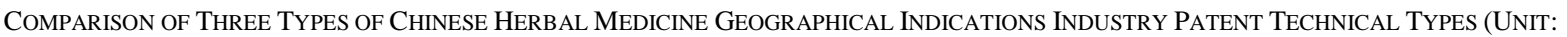
PIECES)

\begin{tabular}{|c|c|c|c|c|c|c|c|c|}
\hline $\begin{array}{ll}\text { Technical Types } & \text { Patent Type } \\
\end{array}$ & \multicolumn{2}{|c|}{ Invention Patents } & \multicolumn{2}{|c|}{ Utility Model Patents } & \multicolumn{2}{|c|}{ Design Patents } & \multicolumn{2}{|c|}{ Subtotal } \\
\hline $\begin{array}{c}\text { Chinese Herbal Medicine Cultivation, Breeding } \\
\text { Technology }\end{array}$ & 33 & $7.4 \%$ & 1 & $0.3 \%$ & 0 & $0.0 \%$ & 34 & $2.0 \%$ \\
\hline Chinese Herbal Medicine Processing Technology & 76 & $17.1 \%$ & 5 & $1.6 \%$ & 0 & $0.0 \%$ & 81 & $4.9 \%$ \\
\hline $\begin{array}{c}\text { Traditional Chinese Medicine Products And } \\
\text { Processing Technology }\end{array}$ & 146 & $32.8 \%$ & 8 & $2.5 \%$ & 0 & $0.0 \%$ & 154 & $9.3 \%$ \\
\hline Chinese Herbal Medicine Related Equipment & 27 & $6.1 \%$ & 242 & $76.1 \%$ & 1 & $0.1 \%$ & 270 & $16.2 \%$ \\
\hline $\begin{array}{c}\text { Traditional Chinese Medicine Derivative Products } \\
\text { And Process Methods }\end{array}$ & 45 & $10.1 \%$ & 8 & $2.5 \%$ & 3 & $0.3 \%$ & 56 & $3.4 \%$ \\
\hline Traditional Chinese Medicine Packaging & 0 & $0.0 \% \%$ & 7 & $2.2 \%$ & 890 & $98.9 \%$ & 897 & $53.9 \%$ \\
\hline $\begin{array}{c}\text { Chinese Medicine Quality Testing Equipment And } \\
\text { Method }\end{array}$ & 41 & $9.2 \%$ & 1 & $0.3 \%$ & 0 & $0.0 \%$ & 42 & $2.5 \%$ \\
\hline Other Categories & 77 & $17.3 \%$ & 46 & $14.5 \%$ & 6 & $0.7 \%$ & 129 & $7.8 \%$ \\
\hline
\end{tabular}

"Table I" shows that the geographical indications industry of Chinese herbal medicine has been authorized in the patent, of which the invention patents are mainly distributed in the traditional Chinese medicine products and processing technology (32.8\%), and Chinese herbal medicine processing technology $(17.1 \%)$; utility model patents are mainly concentrated in the Chinese herbal medicine Equipment (76.1\%); design patents are mainly concentrated in the field of traditional Chinese medicine packaging $(98.9 \%)$. In this case, the largest number of traditional Chinese medicine packaging patent (897) accounts for 53.9 percentage of the total number of authorized patents. The sum of the total number of patents in the first three categories of technology is 269, accounting for 16.2 percentage points of the total number of authorized patents, less than $1 / 3$ of the traditional Chinese medicine packaging. These data show that the geographical indications of Chinese herbal medicine industry patents are more distributed in the traditional Chinese medicine packaging, while the number of technical patents is low.

\section{ANALysis On LEGAl Status AND MaintenANCE INFORMATION OF CHINESE HERBAL MEDICINE GEOGRAPHICAL INDICATIONS INDUSTRY HAS AUTHORIZED PATENTS}

\section{A. Legal Status of the Authorized Patents}

According to the provisions of the Patent Law of the People's Republic of China, the legal status of the authorized patents can be divided into six kinds of situations such as "continuing effective" "termination" "expiration" "invalid" "revocation" "(as) to give up"1. Article 44, paragraph 1, of the Patent Law states: "Under any of the following circumstances, the patent right shall be terminated before the expiration of the duration: (1) failure to pay the annual fee as required; or (2) the patentee waiving of the patent right by a written declaration." According to this provision, no annual fee can be automatically reached the purpose of the termination of the patent. The majority of patentees generally

The data collected show that there is no "revocation" in the relevant patent information of the geographical indications industry of Chinese herbal medicine, so this article will not be set up for data analysis. do not pay the annual fee to terminate their patent rights 2 . The data show that there are 1036 patents, which are still "valid", and 627 patents that have lost legal effect (including termination, expiration, invalid, and (as) to give up) in the authorized patent, the failure rate is $39.5 \%$. The legal status is shown in "Table II".

"Table II" shows that from the invention patent to the utility model patent and then to the design patent, which continues to be effective downward trend, the termination rate is an increasing trend. The invention has the highest efficiency $(92.1 \%)$ and the lowest termination rate $(7.4 \%)$. The design patent was the least efficient $(39.3 \%)$ and had the highest rate of termination $(56.4 \%)$. To avoid duplication of authorization, utility model patents to give up have reached the rate of $2.2 \%$. At the same time, the invention patents and utility model patents are full of zero, while invention patents and design patents are individually invalid. The number of patents (900 pieces) has been the largest in the authorized patents, but the stability of the rights is the worst, and the stability of the invention patent is the best, but the proportion is small.

\footnotetext{
2 But sometimes the patentee for a certain purpose, will also be adopted by submitting a statement to give up its patent, that is, "(as) to give
} up." 


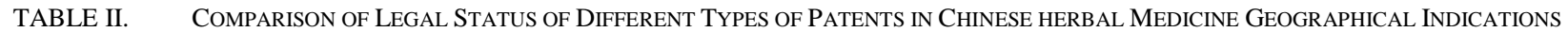

\begin{tabular}{|c|l|l|l|l|l|l|l|l|l|l|}
\hline Legal Status & \multicolumn{2}{|c|}{ Continuing Effective } & \multicolumn{2}{|c|}{ Termination } & \multicolumn{2}{c|}{ Expiration } & \multicolumn{2}{c|}{ Invalid } & (As) To Give Up \\
\hline Patent Type & 410 & $92.1 \%$ & 33 & $7.4 \%$ & 0 & $0.0 \%$ & 2 & $0.4 \%$ & 0 & $0.0 \%$ \\
\hline Invention Patents & 272 & $85.5 \%$ & 39 & $12.3 \%$ & 0 & $0.0 \%$ & 0 & $0.0 \%$ & 7 & $2.2 \%$ \\
\hline Utility Model Patents & 354 & $39.3 \%$ & 508 & $56.4 \%$ & 37 & $4.1 \%$ & 1 & $0.1 \%$ & 0 & $0.0 \%$ \\
\hline Design Patents & $35 \%$
\end{tabular}

Expired patent maintenance time. Patent maintenance time is the actual time from the date of application or the date of authorization to the date of invalidation, termination, revocation or expiration [12]. Patent maintenance time is an important factor in measuring patented technology and economic value. The easiest way to identify a patent value is usually to see how long the patentee maintains the patent. The patent law stipulates that the patent right is required to pay the patent annual fee, and for the patented technology with no income or no potential income, the right holder is generally reluctant to continue to pay the annual fee and maintain it for a long time. In other words, if the patentee to the last year of the patent period is still paid annual fee patent, it is often the most valuable patent. Therefore, through the analysis of Chinese herbal medicine geographical indications industry patent maintenance time can effectively know the industry's patent quality. The Expired patent maintenance time is shown in "Table III".

TABLE III. COMPARISON OF THE MAINTENANCE TIME OF THE THREE TYPES OF EXPIRED PATENTS OF CHINESE HERBAL MEDICINE GEOGRAPHICAL INDICATIONS INDUSTRY (UNIT: PIECES) ${ }^{3}$

\begin{tabular}{|c|l|l|l|l|l|l|}
\hline $\begin{array}{c}\text { Maintenance } \\
\text { time (years) }\end{array}$ & \multicolumn{2}{|c|}{$\begin{array}{c}\text { Invention } \\
\text { Patents }\end{array}$} & \multicolumn{2}{c|}{$\begin{array}{c}\text { Utility } \\
\text { Model } \\
\text { Patents }\end{array}$} & \multicolumn{2}{c|}{$\begin{array}{c}\text { Design } \\
\text { Patents }\end{array}$} \\
\hline $\mathbf{0 - - 1}$ & 2 & $5.7 \%$ & 6 & $13.0 \%$ & 30 & $5.5 \%$ \\
\hline $\mathbf{2 - - 3}$ & 5 & $14.3 \%$ & 28 & $60.9 \%$ & 249 & $45.6 \%$ \\
\hline $\mathbf{4 - - 5}$ & 14 & $40.0 \%$ & 5 & $10.9 \%$ & 89 & $16.3 \%$ \\
\hline $\mathbf{6 - - 7}$ & 13 & $37.1 \%$ & 1 & $2.2 \%$ & 62 & $11.4 \%$ \\
\hline $\mathbf{8 - - 9}$ & 1 & $2.9 \%$ & 6 & $13.0 \%$ & 79 & $14.4 \%$ \\
\hline $\mathbf{1 0 - - 1 1}$ & 0 & $0.0 \%$ & 0 & $0.0 \%$ & 37 & $6.8 \%$ \\
\hline $\mathbf{1 2 - - 1 4}$ & 0 & $0.0 \%$ & 0 & $0.0 \%$ & 0 & $0.0 \%$ \\
\hline total & 35 & $100 \%$ & 46 & $100 \%$ & 546 & $100 \%$ \\
\hline
\end{tabular}

"Table III" shows that the invention patent and utility model patent maintenance time is relatively short, the invention patent to maintain the majority of 4-7 years, utility model patents only to maintain the majority of 2-3 years was terminated, no one invention patent and utility model patents is held for more than 10 years. On the whole, in the case of patent for invalidation, the patentee (enterprise) is reluctant to pay the annual fee for the patent so that the relevant patent is maintained for a long time, reflecting the low value of the technology patent. Different from the technical patent that is the design patent with the maintenance of the delay, although the number of declining trend, the transition is relatively stable. Some of the design patents $(25.8 \%)$ were maintained for 6-9 years, and some of them (6.8\%) were able to maintain the expiry of the patent protection period, indicating that there was a certain amount of high-value design patents in the expired patent. However, it is worth noting that the design patent is maintained at 2-3 years also occupies a large proportion (45.6\%).

The data collected show that the authorized duration of the patent is up to 14 years, so the maintenance period is only 14 years.

\section{B. Continue Effective Patent Maintenance Time}

Chinese herbal medicine geographical indications industry of having authorized the patent data show that the patent is still effective a total of 1036 , the effective rate of $60.5 \%$, which accounted for $39.6 \%$ of invention patents, utility model patents accounted for $26.3 \%$, design patents accounted for $34.2 \%$. The effective patent maintenance time is shown in "Table IV".

TABLE IV. COMPARISON OF THE MAINTENANCE TIME OF THE Continuing PATENT OF CHINESE HERBAL MEDICINE GEOGRAPHICAL INDICATIONS INDUSTRY

\begin{tabular}{|c|l|l|l|l|l|l|}
\hline $\begin{array}{c}\text { Maintenance } \\
\text { time (years) }\end{array}$ & \multicolumn{2}{|c|}{$\begin{array}{c}\text { Invention } \\
\text { Patents }\end{array}$} & \multicolumn{2}{c|}{$\begin{array}{c}\text { Utility } \\
\text { Model } \\
\text { Patents }\end{array}$} & \multicolumn{2}{c|}{$\begin{array}{c}\text { Design } \\
\text { Patents }\end{array}$} \\
\hline $\mathbf{0 - - 1}$ & 141 & $34.4 \%$ & 173 & $63.6 \%$ & 135 & $38.1 \%$ \\
\hline $\mathbf{2 - - 3}$ & 126 & $30.7 \%$ & 84 & $30.9 \%$ & 104 & $29.4 \%$ \\
\hline $\mathbf{4 - 5}$ & 88 & $21.5 \%$ & 14 & $5.1 \%$ & 103 & $29.1 \%$ \\
\hline $\mathbf{6 - - 7}$ & 43 & $10.5 \%$ & 1 & $0.4 \%$ & 8 & $2.3 \%$ \\
\hline $8--9$ & 8 & $1.9 \%$ & 0 & $0.0 \%$ & 1 & $0.3 \%$ \\
\hline $\mathbf{1 0 - - 1 1}$ & 4 & $1.0 \%$ & 0 & $0.0 \%$ & 1 & $0.3 \%$ \\
\hline $\mathbf{1 2 - - 1 4}$ & 0 & $0.0 \%$ & 0 & $0.0 \%$ & 2 & $0.6 \%$ \\
\hline total & 410 & $100 \%$ & 272 & $100 \%$ & 354 & $100 \%$ \\
\hline
\end{tabular}

"Table IV" shows that all patents with the maintenance of the adjourned, the volume was declining trend. Whether it is invented patents, utility model patents, or design patents, which continue to be effective in the patent to maintain the majority of 5 years, and the maintenance time has not yet more than 1 year $(0-1)$ a large proportion of the patent. The above patent is still valid and therefore can't be finalized based on the maintenance of the overall quality of the part of the patent, but it can also be found: The number of effective invention patents has been slightly higher than the design patent, especially in the past three years to maintain the technical patents that have a higher proportion, indicating that Chinese herbal medicine geographical indications industry of technology innovation capacity has improved in recent years. From the maintenance point of view, this industry patent layout and quality have changed, but on the whole, the effect is still relatively low, Chinese herbal medicine geographical indications industry to maintain longterm high-quality patents are still less.

\section{CONCLUSION}

This study shows that the development of geographical indications of Chinese herbal medicine is obviously insufficient in China; the potential of this industry needs to be further excavated. At the same time, the industry's patent coverage is narrow, the approved use of patents in the enterprise accounted for only $28 \%$, industry patents at a low level (only 2237, which has authorized 1663 patents), which is highly patented modern pharmaceutical industry Dependency characteristics are not consistent. 
In the authorized patent quality issues, through data analysis found: First, the geographical indications of Chinese herbal medicine industry invention patents accounted for less, the existing patents are mainly concentrated in the design field (Chinese herbal medicine packaging); Second, in the legal status of authorized patents and maintenance of information, the maintenance time is generally short, and no one invention patent to maintain more than 10 years, which continued effective patent maintenance time no more than 5 years accounted for a large proportion and the number of high-value technology patents that can be maintained for a long time is minimal. The data show that the patent quality of Chinese herbal medicine geographical indications industry is still at a low level in China.

Based on this situation, Chinese herbal medicine geographical indications of industry hoping to grow and develop, should not only just stay in the protection of geographical indications of Chinese herbal medicine resources, but also need to further emphasize the industry's patent issues. We should fully combine the special characteristics of Chinese herbal medicine geographical indication products, strengthen technology research and development, innovation, and continuously enhance the technical level of products and patent quality, through the use of patent strategy to promote the geographical indications of Chinese herbal medicine industry to take a new path of development.

\section{ACKNOWLEDGEMENT}

This research was financially supported by Guizhou Provincial Education Department Humanities and Social Sciences Base Project and China National Natural Science Fund Project. Project Name: Study on Branding Mechanism of Geographical Indications of Agricultural Products in Guizhou (No.2016JD042); Patent Maintenance Mechanism and Maintenance Law Empirical Study (No. 71373221).

\section{REFERENCES}

[1] LONG xiao-ning, WANG jun, The Motivation and Quality Effect of Chinese Patent Surge, The Journal of World Economy. 6(2015)115141

[2] LI zhu-ming, Patent Strategy in Geographical Indication Industry, China Invention \& Patent. 7(2008)53-54

[3] YANG de-qiao. On Construction and Security Mechanism of Intellectual Property Synergistic Strategy of Geographical Indications, Research of Agricultural Modernization. 5(2012)341-345

[4] Graf.S.W., Improving Patent Quality through identification of relevant prior art: approaches to increase information flow to the patent, Lewis \& Clark Law Review. 11 (2007)495-595

[5] TRAPPEY, A. J. C., C. V. TRAPPEY, C.-Y. WU AND C.-W. LIN, A patent quality analysis for innovative technology and product development, Advanced Engineering Informatics. 26(2012)26-34.

[6] ZHU xue-zhong, Dialectical Perspective of Patent Quantity and Quality in China, Bulletin of Chinese Academy of Sciences. 4(2013)435-441.

[7] QIAO yong-zhong, TAN wan-lin, Empirical Studies of the Relationship of the Claims Number and the Maintenance Time of Patents: Based on the Data of Patents Granted by China and Japan, Science of Science and Management of S.\&T.. 2(2017)77-86.
[8] GENG sheng-yan, GENG li-dong, OUYANG xue-yu, Status Analysis and Countermeasure Research for Patent Application Quality of Traditional Chinese Medicine, Chinese Journal of Information on Traditional Chinese Medicine. 1(2016)18-22.

[9] MA yun-yun, DAN yang, SUN zhi-yi, et al, Development Analysis of Fructus Lycii in the Perspective of Invention Patent, Modern Chinese Medicine. 5(2016)541-546.

[10] ZHANG dong, Perspective on the Bottleneck of New Development of Traditional Chinese Patent Technology-From the Perspective of Patent of Traditional Chinese Medicine, Intellectual Property. 4(2009)78-82.

[11] WU fei-fei, ZHANG guang-an, ZHANG hui, et al, Patent Quality Evaluation Index: an Case of Chinese Bio-pharmaceutical Industry, Science \& Technology Progress and Policy. 7(2014)125-129.

[12] QIAO yong-zhong, Empirical Analysis of the Maintenance Time of Patents Granted by Different Countries in the Technological Field of Chemical Metallurgy, Journal of Intelligence. 6(2015)33-37. 